\title{
Population Aging Can Aggravate Air Pollution: Evidence from China
}

\author{
Hui Shi ${ }^{1}$ \\ ${ }^{1}$ College of Economics and Management, Nanjing University of Aeronautics \& Astronautics, Jiangsu, China \\ Correspondence: Hui Shi, College of Economics and Management, Nanjing University of Aeronautics \& \\ Astronautics, No. 29, Jiangjun Boulevard, Jiangning District, Nanjing City, Jiangsu Province, China. Tel: \\ 1-565-167-1565. E-mail: 15651671565@163.com
}

Received: November 17, 2018

Accepted: December 12, 2018

Online Published: December 30, 2018

doi:10.5539/ijef.v11n2p41

URL: https://doi.org/10.5539/ijef.v11n2p41

\begin{abstract}
Population, resources and environment have always attracted much attention from the society. Nowadays, pollution and population aging are urgent problems to be solved in China, and many scholars have found a strong correlation between pollution and aging. This paper constructs a KAYA model with aging variables, making an empirical analysis of the relationship between population aging and air pollution based on the panel data of 82 cities in China from 2011 to 2016. We found that population aging has a significant and positive impact on air pollution. $1 \%$ change of the population aging will lead to a $0.203 \%$ change in AQI. The deepening of China's aging level will lead to ineffective improvement of air quality and even lead to more serious air pollution. Then we make the further analysis of the impact mechanism of population aging on air quality, the results show that population aging could have a positive impact on air pollution by improving labor productivity, promoting technological innovation, increasing fossil energy consumption and the household consumption, and changing the structure of household consumption. At last, in order to improve the air pollution under the background of population aging, we put forward the policy recommendations according to the conclusion of this paper.
\end{abstract}

Keywords: population aging, air pollution, KAYA equation, mediation effect

\section{Introduction}

Since the reform and opening up, the China's economy has experienced rapid development in the past 30 years. In 2010, it surpassed Japan and became the world's second largest economy after the United States. China's total GDP accounted for $15.05 \%$ of the world's total in 2017. However, behind the rapid development is the extensive economic development model with high energy consumption and serious pollution, which caused serious environmental and air pollution problems. According to the "2017 China Environmental Bulletin", 254 cities have exceeded the standard air quality among the total 338 cities, the over-standard rate is as high as $70.7 \%$. While China is experiencing rapid economic development and air pollution problems, the problem of population aging is gradually emerging. Since the middle of the 1970s, China has entered the "golden period" of population, and the demographic dividend effect was significant. However, it took China only 25 years to complete the transformation of the population growth model that developed countries need to complete more than 40 years. When China entered the aging society in 2000, its per capita GDP was less than 1000 dollars, which means the current level of economic development in China does not match the age structure of population. China will face a situation of "get old before getting rich" for a long time in the future. According to UN statistics, China's population aged 60 and over will reach 500 million in 2050, China will enter a super-age society at that time.

With the aging of the population, the increase in the number and proportion of the elderly population will change the level and the structure of social consumption, the input of enterprises and the mode of production, which can directly or indirectly effect the air pollution. Recently, more and more scholars have put their eyes on the age structure of the population when studying the population factors affecting the pollution. They have found through strong rigorous evidence that there is a strong correlation between aging and pollution. Wang (2013) used the extended KAYA model to find that the impact of population aging on environmental pollution is an inverted U-shaped curve, the initial stage of aging will increase environmental pollution, while the long-term continuous population aging will inhibit the pollution emissions. Buehn (2013) conducted a study on the influencing factors of air pollution by using the MIMIC model, and found that population aging has a positive impact on air quality. Like Buehn's conclusion, Li (2014) adjusted and expanded of the EKC model, empirically 
found that the increase of the proportion of the elderly population will play a positive role in the improvement of air quality. $\mathrm{Mu}(2016)$ also used the EKC curve but got the different conclusions: the larger scale of old population, the higher the level of economic development required to improve the environmental pollution, and when the per capita GDP level is fixed, the deepening of the population aging will lead to more serious environmental pollution.

China has regarded the pollution prevention and control as one of the three major battles in the next three years, the "blue sky defense war" is even more important. At the same time, it also proposes to actively respond to the aging population and attach great importance to the rapid development of the aging population, which means environmental pollution and population aging are urgent problems in China during the current period. Therefore, it is significant to sort out the relationship between population aging and air pollution. This paper constructs a KAYA model with aging variables, and uses the panel data of 82 cities in China in 2011-2016 to empirically analyze the relationship between population aging and air pollution. Then the mediating effect model is used to explore its influence mechanism. According to the conclusions, we put forward corresponding policy recommendations for the treatment of air pollution in China under the background of aging.

\section{Model Construction and Variable Selection}

\subsection{Improved KAYA Model}

KAYA's identity was proposed by Japanese scholar Kaya (1989) at a seminar organized by the UN's Office of Climate Change (IPCC). The equation breaks down carbon dioxide emissions into four elements related to human production and life through a simple mathematical formula:

$$
C=P \times \frac{G D P}{P} \times \frac{E}{G D P} \times \frac{C}{E}
$$

Where $\mathrm{C}$ is the amount of carbon dioxide emissions, $\mathrm{P}$ is the total population, GDP is the gross domestic product, and $\mathrm{E}$ is the total energy consumption. GDP/P is per capita GDP, E/GDP represents energy consumption per unit of GDP, and $\mathrm{C} / \mathrm{E}$ represents carbon dioxide emission intensity.

In real life, in addition to population size, population factors also include population structure. The inclusion of demographic variables makes the study of population factors affecting air pollution more realistic. Therefore, based on KAYA's identity, this paper expands the population factor into population size and population aging, and takes population urbanization as a control variable. The adjusted KAYA equation is as follows:

$$
\mathrm{AP}=P_{(\text {amount,age,urban })} \times \frac{G D P}{P_{(\text {amount,age,urban })}} \times \frac{E}{G D P} \times \frac{A P}{E}
$$

In order to eliminate the fluctuation trend of the variables and reduce the heteroscedasticity, this paper takes the logarithm of each side of the equation and obtains the following equation:

$$
\ln \mathrm{AP}=\ln P_{(\text {amount,age,urban })}+\ln G D P P+\ln E G D P+\ln A P E
$$

Based on this, add other control variables to establish the measurement model:

$$
\ln A P_{i t}=\alpha_{1} \operatorname{lnage}_{i t}+\beta \ln X_{i t}+\gamma_{i}+\mu_{t}+\varepsilon_{i t}
$$

age represents the population aging variable, $X$ includes: population factors such as population size and population structure; economic factors such as per capita GDP; energy factors such as energy consumption structure, energy consumption per unit of GDP, pollution emission intensity and other control variables, $u$ is the error term; the subscript $i$ represents the city and trepresents the year.

\subsection{Selection of Variables}

\subsubsection{Core Variables}

The level of air pollution is measured by the Air Quality Index (AQI), which represents the air quality status of the city in the short term and its changing trends. The six pollutants involved in evaluation are $\mathrm{PM}_{10}, \mathrm{PM}_{2.5}, \mathrm{SO}_{2}$, $\mathrm{NO}_{2}, \mathrm{O}_{3}$ and $\mathrm{CO}$. The AQI range is from 0 to 500. The pollutants larger than 100 are excessive pollutants. The larger the AQI value, the higher the pollution level.

We take the proportion of permanent residents aged 65 and above as the indicator of aging population (Note 1). In order to test correlation degree between AQI and population aging, the grey absolute correlation degree is calculated by using grey modeling software, the result is 0.5481 , which shows that there is a certain correlation between them. Figure 1 is a scatter plot of AQI and population aging drawn by Stata, which are roughly in an upwardly sloping line, so we assume a positive correlation between the two. 


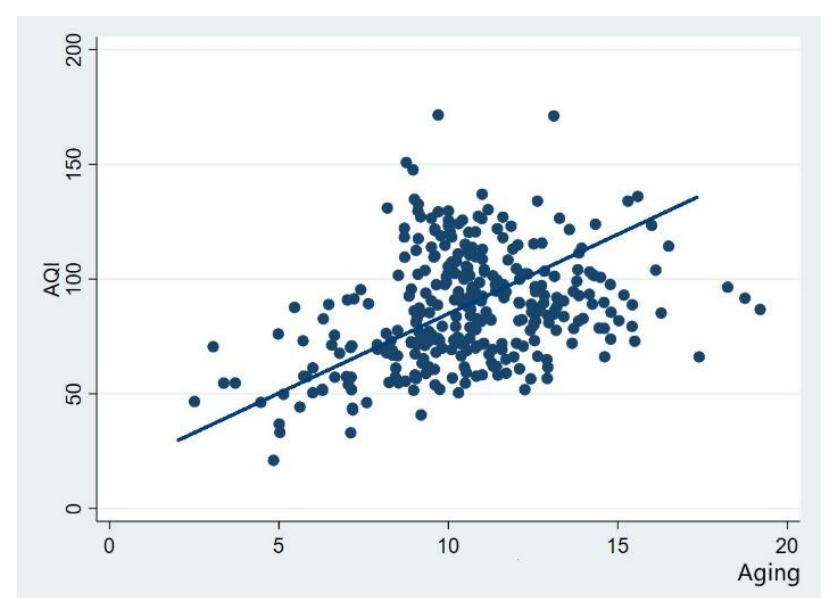

Figure 1. Scatter plot of AQI and population aging level

\subsubsection{Control Variables}

In addition to selecting the basic variables in the KAYA identities such as population size (pop), per capita GDP (gdpp), unit GDP energy consumption (egdp), and air pollution emission intensity (aqie) as control variables, according to relevant literature and theoretical analysis(Yu,2017;Wang,2012), We also selected variables such as fossil energy consumption proportion(fossil), population density (pd) and urbanization(urban) as the control variables.

\subsection{Data Sources and Descriptive Statistics}

The AQI data of this paper comes from the Information Center of the Ministry of Environmental Protection of the People's Republic of China. Since the AQI index was introduced in China in the first half of 2012, considering the reliability and availability of data, the time span selected in this paper is 2012-2016. Other explanatory variables such as population aging, population size, GDP, and energy consumption are derived from the 2013-2017 statistical yearbooks. Due to the lack of statistical data and statistical standards in some cities, the final sample was included in 82 cities, with a total of 328 samples.

Table 1. Statistical description of variables

\begin{tabular}{cccccc}
\hline variable & unit & mean & standard deviation & minimum & Maximum \\
\hline AQI & $/$ & 86.60 & 24.22 & 21.01 & 171.54 \\
PM $_{2.5}$ & $\mu \mathrm{g} / \mathrm{m}^{3}$ & 60.98 & 22.03 & 21.00 & 148.5 \\
aging & $\%$ & 10.55 & 2.60 & 2.51 & 19.2 \\
pop & ten thousand & 666.17 & 470.33 & 57.25 & 3048.43 \\
gdpp & Yuan/person & 69303.65 & 30644.21 & 6684 & 167411.2 \\
egdp & ton standard coal / ten thousand Yuan & 0.619 & 0.287 & 0.20 & 1.776 \\
aqie & $/$ & 0.066 & 0.054 & 0.005 & 0.44 \\
fossil & $\%$ & 86.11 & 9.80 & 35.08 & 99.11 \\
pd & People/ sq.km. kilometer & 773.86 & 762.05 & 98.37 & 5962.34 \\
urban & $\%$ & 65.11 & 13.98 & 34.70 & 100 \\
\hline
\end{tabular}

\section{Empirical Test}

\subsection{Population Aging and Air Pollution}

In order to empirically analyze the relationship between population aging and air quality, panel data model was used for regression estimation. Since the range of the interpreted variable AQI is 0 500, for the model whose dependent variable is a restricted variable and the lower limit is 0 , the panel data is usually estimated by Tobit regression. We use stata 15.0 to do the empirical test. The results of the regression are shown in table 2. 
Table 2. Estimates of the relationship between aging and AQI

\begin{tabular}{cccc}
\hline Variable & Model 1 & Model 2 & Model 3 \\
\hline Ln pop & $0.649(7.51)^{* * *}$ & $0.638(7.71)^{* * * *}$ & $0.636(8.48)^{* * * *}$ \\
Ln gdpp & $0.133(4.50)^{* * *}$ & $0.116(4.13)^{* * *}$ & $0.104(3.67)^{* * *}$ \\
Ln egdp & $0.091(1.71)^{*}$ & $0.240(4.14)^{* * * *}$ & $0.286(4.75)^{* * *}$ \\
Ln aqie & $0.777(24.79)^{* * *}$ & $0.779(27.02)^{* * *}$ & $0.764(25.69)^{* * *}$ \\
Ln urban & $/$ & $0.876(6.11)^{* * *}$ & $0.896(6.39)^{* * *}$ \\
Ln pd & $/$ & $0.069(0.91)$ & $/$ \\
Ln fossil & $/$ & $0.878(4.43)^{* * *}$ & $0.769(3.89)^{* * *}$ \\
Ln aging & $/$ & $/$ & $0.203(2.64)^{* * *}$ \\
Constant & $-6.538(-7.10)^{* * *}$ & $-15.216(-10.35)^{* * *}$ & $-14.903(-10.54)^{* * *}$ \\
Log likelihood & 122.098 & 148.237 & 151.277 \\
LR chi2(1) & 289.43 & 317.54 & 278.76 \\
$\mathrm{R}^{2}$ & 0.964 & 0.958 & 0.955 \\
\hline
\end{tabular}

Note. The z-values in parentheses after the regression coefficient, *, **, *** represent significant at the level of $10 \%, 5 \%$, and $1 \%$ respectively.

Model 1 is the benchmark model, which mainly investigates the influence of control variables on the air quality in the KAYA identity model. Model 2 adds the control variables like fossil energy consumption proportion, population density and population urbanization rate. Then remove the variable with no significant regression in model 2 ( $p>0.1$ ) to obtain a modified model. Based on model 2, model 3 adds population aging to measure the impact of aging population on air pollution.

The revised model 3 regression results show that the population aging variable has passed the significance test with a confidence level of $1 \%$. $1 \%$ change in the proportion of people aged 65 and over will cause AQI to change by $0.203 \%$ in the same direction. The degree of air pollution will increase with the deepening of aging.

The positive effects of population aging on air pollution can be caused by the following three reasons:

First of all, recently China has gradually opened up the two-child policy to increase fertility, and improve the age structure of the population, so as to solve the main contradictions of the current population in China. However, the lagging influence of the family planning policy for more than 30 years has also made the fertility rate increase more slowly. Therefore, although the proportion of the labor force in China has a slight downward trend, its total number is still rising and has a large base, what's more, the longer life span of the population leads to the continued participation of middle-aged and elderly people in social work. So the aging of the population at this stage will not inhibit the production and consumption of society, and thus will not reduce the emission of various pollutants (Zhang, 2016).

Secondly, the increase in the proportion of the elderly population will stimulate the demand for medical care, nursing and health care. And as the life expectancy increases, the health level improves and the living conditions improve, the old people may increase their travel and education expenses. These needs will further stimulate social consumption and increase energy consumption, which can lead to more pollutant emissions and serious air pollution.

Finally, at this stage, the elderly in China are not willing to pay for the improvement of environmental quality, because the improvement of the environment is a relatively long-term process, which is more conducive to the quality of life of the future population, while the elderly have to bear the current treatment costs but cannot enjoy the improvement result immediately, this is the reason why the elderly are less willing to pay for the environment (Zhang, 2016). Therefore, the deepening of aging will hinder the implementation of pollution control policies to some extent.

For the other control variables, the benchmark variables in the KAYA model such as the total population, per capita GDP, energy consumption per unit of GDP, and air pollution emission intensity have a significant and positive impact on air pollution, indicating that the rapid development of China's economy and the continuous growth of population are accompanied by mass production, which caused high emissions and serious air pollution. The influence of the remaining control variables on AQI is also significant and positive. The acceleration of urbanization will lead to poor air quality, and improving the energy consumption structure and reducing the proportion of fossil energy consumption will promote the improvement of air quality.

In order to further investigate whether the inhibition of air quality improvement by population aging is robust, this paper uses the methods of substituting variables, eliminating endogenous and deleting outliers to estimate 
the regression of sample data.

We use the concentration of $\mathrm{PM}_{2.5}$ in the air as a surrogate variable for AQI, and use the old-age dependency ratio (ratio of the elderly population to the labor population) as a surrogate variable for population aging, then we get model 6 and model 7. The results show that the aging variables have passed the significance test, and the impact on air pollution is still significant and positive, indicating that the above-mentioned conclusion that the degree of aging is proportional to air pollution has certain robustness.

Table 3. Regression results of $\mathrm{PM}_{2.5}$ and age dependency ratio

\begin{tabular}{ccccc}
\hline Variable & Model 4 & Model 5 & Model 6 & Model 7 \\
\hline Ln pop & $0.708(11.46)^{* * *}$ & $0.662(10.39)^{* * *}$ & $0.648(10.33)^{* * *}$ & $0.638(8.49)^{* * *}$ \\
Ln gdpp & $0.014(1.36)$ & $0.015(1.33)$ & $/$ & $0.105(3.73)^{* * *}$ \\
Ln egdp & $0.604(32.51)^{* * *}$ & $0.612(29.02)^{* * *}$ & $0.619(31.24)^{* * * *}$ & $0.284(4.7)^{* * *}$ \\
Ln aqie & $0.695(55.91)^{* * *}$ & $0.699(48.41)^{* * *}$ & $0.703(52.76)^{* * *}$ & $0.763(25.60)^{* * *}$ \\
Ln urban & $/$ & $0.039(0.42)$ & $/$ & $0.896(6.38)^{* * *}$ \\
Ln pd & $/$ & $0.119(2.22)^{* *}$ & $0.131(2.54)^{* *}$ & $/$ \\
Ln fossil & $/$ & $0.015(0.16)$ & $/$ & $0.775(3.91)^{* * *}$ \\
Ln age & $/$ & $/$ & $0.070(1.77)^{*}$ & $0.165(2.46)^{* *}$ \\
Constant & $-8.215(-16.84)^{* * *}$ & $-9.01(-10.32)^{* * *}$ & $-8.820(-16.77)^{* * *}$ & $-14.911(-10.52)^{* * *}$ \\
Log likelihood & 288.794 & 291.323 & 291.906 & 150.825 \\
LR chi2(1) & 517.03 & 480.00 & 526.72 & 277.31 \\
$\mathrm{R}^{2}$ & 0.988 & 0.986 & 0.987 & 0.956 \\
\hline
\end{tabular}

Note. The z-values in parentheses after the regression coefficient, *, **, *** represent significant at the level of $10 \%, 5 \%$, and $1 \%$ respectively.

The endogeneity of the variables may affect the robustness of the regression results. The correlation between the explanatory variables and the residuals may lead to biased and inconsistent regression coefficients. We use the lag phases which have high correlation with the original explanatory variables as a substitute for the current variable, see model 8. In order to reduce the influence of outliers in the sample on the regression results and verify the robustness of the above conclusions, we exclude the cities with the largest and smallest AQI values and the cities with abnormal trend of data variation from the samples to obtain the model 9 . The results show that the main variables are statistically significant. The direction of the estimated coefficients is consistent with the model 3 and the number varies slightly. It can be considered that the regression results obtained above are objective and effective, and the model 3 has strong robustness.

Table 4. Regression results of lag phase and deletion of outliers

\begin{tabular}{ccc}
\hline Variable & Model 8 & Model 9 \\
\hline Ln pop & $0.703(14.88)^{* * *}$ & $0.599(6.88)^{* * *}$ \\
Ln gdpp & $0.027(1.57)$ & $0.083(3.05)^{* * *}$ \\
Ln egdp & $0.705(26.81)^{* * *}$ & $0.313(4.81)^{* * *}$ \\
Ln aqie & $0.727(40.81)^{* * *}$ & $0.767(23.68)^{* * *}$ \\
Ln urban & $0.555(6.68)^{* * *}$ & $0.975(6.23)^{* * *}$ \\
Ln fossil & $0.061(0.57)$ & $0.811(4.03)^{* * *}$ \\
Ln age & $0.130(2.71)^{* * *}$ & $0.319(3.80)^{* * *}$ \\
Constant & $-12.00(-14.16)^{* * *}$ & $-14.903(-10.54)^{* * *}$ \\
Log likelihood & 283.00 & 141.622 \\
LR chi2(1) & 345.38 & 244.30 \\
$\mathrm{R}^{2}$ & 0.985 & 0.9562 \\
\hline
\end{tabular}

Note. The z-values in parentheses after the regression coefficient, *, **, *** represent significant at the level of $10 \%, 5 \%$, and $1 \%$ respectively.

\subsection{Mediating Effect}

In order to further explore how population aging affects air pollution and study its impact mechanism in depth, we use the mediating effect model.

The mediating effect means that the influence of $\mathrm{X}$ on $\mathrm{Y}$ is realized by $\mathrm{M}$, that is to say, $\mathrm{M}$ is a function of $\mathrm{X}, \mathrm{Y}$ is a function of $\mathrm{M}(\mathrm{Y}-\mathrm{M}-\mathrm{X})$. When considering the influence of $\mathrm{X}$ on $\mathrm{Y}$, if $\mathrm{X}$ can influence $\mathrm{Y}$ through $\mathrm{M}$, then $\mathrm{M}$ 
is called the intermediate variable (Wen, 2014). We use the stepwise test regression coefficient method to establish a recursive equation $(6)(7)(8)$ to study the mediators through which population aging affects air quality:

$$
\begin{gathered}
\ln A P_{i t}=\alpha_{1} \text { lnage }_{i t}+\theta \ln X_{i t}+\gamma_{i}+\mu_{t}+\varepsilon_{i t} \\
\ln Z_{i t}=\operatorname{\lambda lnage}_{i t}+\varphi \ln X_{i t}+\gamma_{i}+\mu_{t}+\varepsilon_{i t} \\
\ln A P_{i t}=\alpha_{2} \operatorname{lnage~}_{i t}+\sigma \ln Z_{i t}+\tau \ln X_{i t}+\gamma_{i}+\mu_{t}+\varepsilon_{i t}
\end{gathered}
$$

Equation 5 is the equation to test the relationship between population aging and air quality, we have already got the result that the population aging variable has passed the $1 \%$ significance test. $\mathrm{Z}$ in equation 6 represents each mediator variable, testing the relationship between population aging and mediator variables. If the aging variable in equation 6 passes the significance test, then the population aging has a significant impact on the mediator variable, so we can get into the next step. See equation 7 , the median variable and the population aging variable are included in the equation as the explanatory variable, and the air pollution variable is the explanatory variable. If the mediator variable passes the significance test, then the mediating effect is significant, and at the same time If the aging variable does not satisfy the significance test, the mediator variable $\mathrm{Z}$ is considered to have a complete mediating effect. If the aging variable passes the significance test, the mediator variable is considered to have a partial mediating effect.

This paper will analyze the impact mechanism of population aging on air quality from the aspects of production path, energy consumption path and household consumption path.

\subsubsection{Production Path}

Under the background of population aging, on the one hand, the increase in the proportion of the elderly population leads to a decline in the quantity and growth rate of labor supply. The gradual disappearance of the demographic dividend and the change in the age structure of the population will enable the state to intensify scientific and technological innovation and improve the technological level to cope with the decline in the labor force (Ono \& Maeda, 2001); In terms of the individual aspect, the decline in fertility caused by aging will also allow parents to invest more in their children's education, which can contribute to the improvement of the cultural quality of the young workforce. Therefore, we assume that the aging of the population has a positive effect on technological innovation, and the $\lambda$ direction is positive. We use regional patent filings (Yao et al., 2017) (model 10,11) and enterprise R\&D expenditure accounts for GDP share (Chen et al., 2016) (model 12,13) to measure technological innovation.

Table 5. Mediating effect based on technological innovation

\begin{tabular}{ccccc}
\hline Variable & Model 10 & Model 11 & Model 12 & Model 13 \\
\hline Ln aging & $1.04(4.90)^{* * *}$ & $0.55(7.07)^{* * * *}$ & $0.30(2.63)^{* * *}$ & $0.51(6.51)^{* * * *}$ \\
Ln young & $-1.09(-3.11)^{* * *}$ & $0.36(3.14)^{* * *}$ & $-0.63(-3.53)^{* * *}$ & $0.41(3.56)^{* * *}$ \\
Ln gdpp & $-6.20(-3.75)^{* * *}$ & $-1.37(-1.51)$ & $-1.01(-1.19)$ & $-1.12(-1.27)$ \\
Ln gdpp & $0.31(3.92)^{* * *}$ & $0.07(1.66)^{*}$ & $0.05(1.22)$ & $0.058(1.41)$ \\
Ln egdp & $-0.95(-6.37)^{* * *}$ & $-0.09(-1.55)$ & $-0.26(-3.08)^{* * *}$ & $-0.03(-0.55)$ \\
Ln fossil & $-0.23(-0.42)$ & $0.35(2.15)^{* *}$ & $-0.02(-0.06)$ & $0.35(1.54)$ \\
Ln Z & $/$ & $-0.03(-1.25)$ & $/$ & $0.07(1.86)^{*}$ \\
Constant & $47.23(5.37)^{* * *}$ & $7.99(1.65)^{*}$ & $8.31(1.82)^{*}$ & $5.99(1.29)$ \\
Log likelihood & -170.21 & 14.54 & 17.73 & 30.27 \\
LR chi2(1) & 536.82 & 62.44 & 442.20 & 59.70 \\
\hline
\end{tabular}

Note. The z-values in parentheses after the regression coefficient, *, **, *** represent significant at the level of $10 \%, 5 \%$, and $1 \%$ respectively.

Models 11 and 13 show that the impact of population ageing on technological innovation is significant and positive. The patent application does not pass the significance test, but the R\&D expenditure in model 14 passes the $10 \%$ significance test, and the population aging passes the $1 \%$ significance test, indicating that this technological innovation variable has significant and partial mediating effects. If technological progress only improves the output efficiency but not the environmental protection technology, it will aggravate the environmental pollution (Dou \& Zhang, 2015).

\subsubsection{Energy Consumption Path}

Most of the $\mathrm{SO}_{2}$ and $\mathrm{PM}_{2.5}$ that constitute air pollution are emitted from the process of energy consumption, especially coal combustion. Therefore, improving the energy consumption structure and promoting the use of 
clean energy have a great effect on improving air pollution. We expect that China's current population aging will lead to an increase in energy consumption, which will further lead to more serious air pollution problems. Therefore, we assume $\lambda>0$, and use the fossil energy consumption as the measure index(Fan, 2015), see model 14 and 15.

Table 6. Mediating effect based on energy consumption

\begin{tabular}{ccc}
\hline Variable & Model 14 & Model 15 \\
\hline Ln aging & $0.23(2.49)^{* * *}$ & $0.57(7.85)^{* * *}$ \\
Ln young & $-0.34(-1.95)^{*}$ & $0.45(4.22)^{* * *}$ \\
Ln gdpp & $-3.54(-5.02)^{* * *}$ & $-0.46(-0.49)$ \\
Ln gdpp & $0.17(5.14)^{* * *}$ & $0.03(0.58)$ \\
Ln egdp & $0.46(7.13)^{* * *}$ & $-0.08(-1.44)$ \\
Ln fossil & $/$ & $/$ \\
Ln Z & $/$ & $0.11(3.76)^{* * *}$ \\
Constant & $22.50(6.11)^{* * *}$ & $3.52(0.72)$ \\
Log likelihood & 71.24 & 18.89 \\
LR chi2(1) & 863.97 & 56.84 \\
\hline
\end{tabular}

Note. The $\mathrm{z}$-values in parentheses after the regression coefficient, *, **, *** represent significant at the level of $10 \%, 5 \%$, and $1 \%$ respectively.

Table 6 shows that population aging has a positive and significant impact on fossil energy consumption. This is consistent with findings from Oneill (2002) and Brounen (2012), which found that older people consume more energy than younger people, and aging is accompanied by higher energy consumption and carbon emission. In model 15, both of the energy consumption variable and population aging have passed the $1 \%$ significance test, and have a positive impact on air pollution, which indicate that fossil energy consumption has a partial and significant mediating effect, aging has led to a decline in air quality by increasing fossil energy consumption.

\subsubsection{Resident Consumption Path}

According to the life cycle theory, the young and middle-aged working population are the net "savings" group, the children are a net "borrowing" group, while the elderly population is relatively "consumer population". In addition, aging will have a certain impact on the consumption structure of residents. Different from the young and middle-aged people, the elderly have a greater demand for medical care, nursing and health care. We use the proportion of resident final consumption to GDP(Zhang, 2013) as an indicator to measure the consumption level of residents, corresponding to model 16 and 17; use the proportion of health care consumption to household consumption expenditure as a measure of consumption structure, corresponding to model 18 and model 19 .

Table 7. Mediating effect based on household consumption

\begin{tabular}{ccccc}
\hline Variable & Model 16 & Model 17 & Model 18 & Model 19 \\
\hline Ln aging & $0.21(4.59)^{* * *}$ & $0.55(7.10)^{* * *}$ & $0.19(2.48)^{* *}$ & $0.52(7.19)^{* * *}$ \\
Ln young & $0.21(2.85)^{* * *}$ & $0.33(3.03)^{* * *}$ & $0.23(0.20)$ & $0.27(2.43)^{* *}$ \\
Ln gdpp & $-0.09(-0.24)$ & $-1.51(-1.65)^{*}$ & $-0.33(-0.46)$ & $-1.72(-1.91)^{*}$ \\
Ln gdpp & $0.003(0.19)$ & $0.08(1.80)^{*}$ & $0.02(0.48)$ & $0.09(2.03)^{* *}$ \\
Ln egdp & $-0.28(-8.39)^{* * *}$ & $0.001(0.03)$ & $0.07(1.18)$ & $-0.02(-0.45)$ \\
Ln fossil & $0.2(2.14)^{* *}$ & $0.28(1.66)^{*}$ & $0.26(1.50)$ & $0.24(1.65)^{*}$ \\
Ln Z & $/$ & $0.27(2.57)^{* * *}$ & $/$ & $0.27(3.76)^{* * *}$ \\
Constant & $3.84(1.96)^{* *}$ & $7.22(1.51)$ & $1.38(0.37)$ & $9.64(2.04)^{* *}$ \\
Log likelihood & 331.54 & 17.31 & 96.09 & 18.95 \\
LR chi2(1) & 506.80 & 70.02 & 206.03 & 31.96 \\
\hline
\end{tabular}

Note. The z-values in parentheses after the regression coefficient, *, **, *** represent significant at the level of $10 \%, 5 \%$, and $1 \%$ respectively.

The results show that the impact of population aging on household consumption level and consumption structure (proportion of medical consumption) is significant and positive. Then we analysis models 19 and 21, the results show that both household consumption level and consumption structure have partial mediating effects and significant mediating effects, which means that aging will reduce air quality by increasing household consumption levels and increasing the proportion of medical consumption. The huge medical needs of the elderly will not only increase the household's consumption expenditure, but also can cause the promotion of 
medical device production and drug research and development, which will require a lot of manpower, material resources and financial resources, resulting in more air problems.

\section{Conclusion}

This paper constructs a KAYA model with aging variables, making an empirical analysis of the relationship between population aging and air pollution based on the panel data of 82 cities in China from 2011 to 2016 . Then we use the mediation effect model to further analysis the influence path of aging population on air quality. The main conclusions are as follows:

1) The population aging has a significant and positive impact on air pollution. For every $1 \%$ change in the proportion of people aged 65 and over, the AQI representing the degree of air pollution will change by $0.203 \%$ in the same direction. Therefore, at this stage in China, the deepening of China's aging will lead to ineffective improvement of air quality and even more serious air pollution.

2) Further analysis of the impact of aging on air quality, we find that labor technology substitution effect, fossil energy consumption, household consumption level and consumption structure all have partial mediating effects and obvious mediating effects. Population aging will have a positive impact on air pollution by promoting technological innovation, increasing fossil energy consumption and household consumption level, and changing household consumption structure.

Based on the empirical results and the conclusions, we put forward the following policy recommendations:

1) Promote the implementation of current fertility policies and alleviate the aging process of the population. China is now gradually implementing the "two child policy", expecting to improve the age structure of the population. Local governments should actively conduct a comprehensive and objective assessment of the local population development situation, formulate scientific implementation plans, and increase the publicity of fertility policies, promote the implementation of the current fertility policy in a safe, solid and orderly way.

2) Accelerate the development and popularization of new energy sources and reduce the proportion of fossil energy consumption. We should accelerate the pace of research and development of clean new energy in China, expand the use of new energy sources such as solar energy, geothermal energy, wind energy, ocean energy, biomass energy and nuclear energy, and increase the proportion of new energy consumption. In terms of the corporations, they should increase investment in science and technology, improve energy efficiency and effectively reduce energy consumption per unit of GDP. What's more, promoting strategic cooperation in international energy and improving China's energy supply system are also very important. Finally, we can actively introduce internationally advanced new energy research and utilization technologies as well as energy-saving and environmentally friendly production models.

3) Improve residents' awareness of environmental protection and vigorously advocate green consumption. Accelerate the construction and development of public transportation such as subways, light rail trams, and new energy buses, improve the service quality and convenience of public transportation, encourage people to take public transportation, so as to reduce exhaust pollution and energy waste caused by private car travel. Also, we should accelerate the development and popularization of energy-saving home appliances and household products, realize the green living and low-carbon life of residents.

This paper incorporates population aging into a unified model, and excavates the ways to improve air quality from the perspective of population aging, which is innovative and has important significance to improve the relevant theories of population, resources and environment. Also, studying the relationship between air pollution and population aging then putting forward corresponding suggestions have important practical significance for promoting action of air pollution prevention and control, accelerating the construction of ecological civilization and promoting sustainable economic development. Limitations of this paper and suggestions for future research are also presented as follows:

1) Due to the limitation of AQI, the time span of sample data selected in this paper is relatively short, and the conclusion may only explain the relationship between population aging and air quality in the current period. In the future, we can lengthen the time series, or find a more scientific and reasonable calculation method to convert the previous monitoring data, so as to expand the number of samples in this paper for further study.

2) The mediation variables in this paper do not include the environmental awareness of the elderly. On the one hand, it is due to the lack of the corresponding statistical indicator, on the other hand, it needs lots of workload to adopt questionnaire survey method. In the future, we can contact the authoritative research institutes related to population and environment in China to seek the help of questionnaire data and the specific implementation of questionnaire work, so as to carry out research from a more micro level. 


\section{References}

Bin, L., \& Tuo, L. (2014). Empirical Study on Kuznets Curve of Air Pollution in China Based on Dynamic Panel System GMM and Threshold Model Test. Economic Issues, 04, 17-22. https://doi.org/10.16011/j.cnki.jjwt.2014.04.001

Brounen, D, Kok, N, Quigley, J. M. (2012). Residential energy use and conservation: Economics and demographics. European Economic Review, 56(5). https://doi.org/10.1016/j.euroecorev.2012.02.007

Bühn, A. (2013). Hold your breath: A new index of air pollution. Energy Economics, 37(1), 104-113. https://doi.org/10.1016/j.eneco.2013.01.011

Chen, C., Jianguo, Y., \& Mengmeng, W. (2016). Rising Labor Cost and Enterprise Growth-Substitution Effect of Technological Innovation. Forecast, 35(01), 8-13. https://doi.org/10.11847/fj.35.1.8

Chuanguo, Z., \& Zheng, T. (2016). The relationships between population factors and China's carbon emissions: Does population aging matter. Renewable and Sustainable Energy Reviews, 65, 1018-1025. https://doi.org/10.1016/j.rser.2016.06.083

Dongzhang, Y., Jing, N., \& Shiyan, W. (2017). How Aging Affects Technological Innovation. World Economy, 40(04), 105-128.

Fang, W., \& Xing, Z. (2012). Population Structure, Urbanization and Carbon Emissions: An Empirical Study Based on Transnational Panel Data. Population Science of China, 02, 47-56.

Fang, W., \& Xing, Z. (2013). Study on Population Factors Affecting Environmental Pollution in China: Empirical Analysis Based on Interprovincial Panel Data. Southern Population, 28(06), 8-18. https://doi.org//10.3969/j.issn.1004-1613.2013.06.002

Hongmin, F. (2015). Study on the relationship between population age, urban rural structure and air pollution. Liaoning University.

Huaizhong, M., \& Mengyao, Z. (2016). The relationship between population aging, economic growth and environmental pollution. Exploration of Economic Issues, 09, 11-17.

Jianmin, D., \& Ke, Z. (2015). Spatial Dependence, Economic Agglomeration and Urban Environmental Pollution. Economic Management, 37(10), 12-21. https://doi.org/10.19616/j.cnki.bmj.2015.10.004

Kaya, Y. (1989). Impact of carbon dioxide emission control on GNP growth: Interpretation of proposed scenarios. IPCC energy and industry subgroup, response strategies working group.

O'Neill, B. C., \& Chen, B. S. (2002). Demographic determinants of household energy use in the united states. Population and Development Review, 28(10), 53-88. https://doi.org/10.1039/C1EE01722E

Ono, T., \& Maeda, Y. (2001). Is aging harmful to the environment? Environmental \& Resource Economics, 20(2), 113-127. https://doi.org/10.1023/A:1012676227797

Yang, Z. (2013). Study on the impact of aging population on consumption structure. Southwestern University of Finance and Economics.

Yuyang, \& Qiuyue, K. (2017). Empirical study on the relationship between urbanization, population aging and carbon emissions in Beijing, Tianjin and Hebei. Eco-Economy, 33(08), 56-59, 80.

Zhonglin, W., \& Baojuan, Y. (2014). Mediation effect analysis: Method and model development. Progress In Psychological Science, 22(05), 731-745. https://doi.org/10.3724/SP.J.1042.2014.00731

\section{Note}

Note 1. Due to the large population mobility of Chinese cities, when choosing the measurement indicators of population aging, the proportion of permanent residents rather than the proportion of registered population is more able to reflect the real population aging in the local area.

\section{Copyrights}

Copyright for this article is retained by the author(s), with first publication rights granted to the journal.

This is an open-access article distributed under the terms and conditions of the Creative Commons Attribution license (http://creativecommons.org/licenses/by/4.0/). 